\title{
Comportamento fitotécnico da bananeira 'Prata-Anã' e de seus híbridos
}

\author{
Sérgio Luiz Rodrigues Donato(1), Alessandro de Magalhães Arantes ${ }^{(1)}$, \\ Sebastião de Oliveira e Silva ${ }^{(2)}$ e Zilton José Maciel Cordeiro ${ }^{(2)}$
}

(1)Instituto Federal de Educação, Ciência e Tecnologia Baiano, Campus Guanambi, Caixa Postal 009, Distrito de Ceraima, CEP $46430-000$
Guanambi, BA. E-mail: sergiodonatoeaf@yahoo.com.br, arantes2005@yahoo.com.br (2)Embrapa Mandioca e Fruticultura Tropical, Caixa
Postal 007, Rua Embrapa s/no, CEP 44380-000 Cruz das Almas, BA. E-mail: ssilva@cnpmf.embrapa.br, zilton@cnpmf.embrapa.br

Resumo - O objetivo deste trabalho foi avaliar o comportamento fitotécnico da bananeira 'Prata-Anã' e de quatro híbridos descendentes, em dois ciclos de produção, no Perímetro Irrigado do Estreito, sudoeste da Bahia. Utilizou-se o delineamento experimental inteiramente casualizado com cinco tratamentos: cultivar Prata-Anã e os híbridos Fhia-01 (BRS Fhia Maravilha), BRS Fhia-18, Fhia-18 e PA42-44, com dez repetições. Foram mensurados os descritores fenotípicos vegetativos, os de ciclo e os de rendimento. Foram observados os seguintes incrementos entre ciclos: na altura da planta, no perímetro do pseudocaule, no número de pencas e de frutos, e na produtividade. O híbrido Fhia-18 apresentou maior porte e perímetro do pseudocaule, a 'Prata-Anã' menor porte (com manutenção desse caráter no PA42-44). Os híbridos foram similares quanto ao número de filhos emitidos. Os híbridos BRS Fhia-18, Fhia-1 e PA42-44 foram mais precoces para a colheita e apresentaram frutos com maior comprimento que a genitora. Fhia-18 apresentou maior quantidade de frutos e PA42-44 menor número de pencas em comparação à genitora. Os híbridos BRS Fhia-18, Fhia-18 e Fhia-1 são mais produtivos que a genitora. 'Prata-Anã' é a mais suscetível à sigatoka-amarela, e PA42-44 é resistente e com maior retenção de folhas na colheita, porém, similar à genitora em produtividade.

Termos para indexação: Musa, caracteres agronômicos, cultivares tipo Prata.

\section{Phytotechnical behavior of 'Prata-Anã' banana and progeny hybrids}

\begin{abstract}
The objective of this work was to evaluate the phytotechnical behavior of 'Prata-Anã' banana and four progeny hybrids, during two production cycles, in the Perímetro Irrigado do Estreito, southwest of Bahia state, Brazil. The experimental design was completely randomized with five treatments: cultivar 'Prata-Anã' and the hybrids Fhia-01 (BRS Fhia Maravilha), BRS Fhia-18, Fhia 18 and PA42-44, with ten replicates. Phenotypic vegetative descriptors, cycle length and yield were measured. Increases occurred between cycles for: plant height, pseudostem perimeter, number of hands and fruits, and yield. The Fhia-18 hybrid showed greater size and pseudostem perimeter, and 'Prata-Anã' had the smallest, (with maintenance of this character in the PA42-44). The hybrids were similar in the number of suckers produced. BRS Fhia-18, PA42-44 and Fhia-1 were early for harvest and had greater fruit length than 'Prata-Anã'. Fhia-18 produced more fruit and PA42-44 had fewer hands compared to the parental cultivar. BRS Fhia-18, Fhia-18 and Fhia-1 are more productive than the parental cultivar. 'Prata-Anã' is more susceptible to yellow sigatoka, while PA42-44 is resistant, with greater retention of leaves at harvest; however, both have similar yields.
\end{abstract}

Index terms: Musa, agricultural characters, Prata type cultivars.

\section{Introdução}

No Brasil, predominam bananas Prata, ao contrário da bananicultura latino-americana de exportação, baseada nas cultivares Cavendish (Silva et al., 2000). Na Região do Semiárido brasileiro, destacam-se os seguintes polos de produção de banana: Minas Gerais - em Janaúba e Jaíba; Bahia - em Juazeiro, Bom Jesus da Lapa, Barreiras, Livramento de Nossa Senhora,
Caraíbas, Guanambi, Urandi e Sebastião Laranjeiras; Pernambuco - em Petrolina e Santa Maria da Boa Vista; Rio Grande do Norte - no Vale do Açu; Sergipe - em Platô de Neópolis; e Ceará - em Chapada do Apodi e Baixo Acaraú.

A área plantada com bananeira no Perímetro Irrigado do Estreito - Urandi e Sebastião Laranjeiras, BA -, em 2008, foi de 1.622 ha, e a produção, de 33,2 mil 
toneladas (Ater, 2008). Aproximadamente 95\% dessa área está cultivada com banana 'Prata', especificamente 'Prata-Anã', cultivar predominante no sudoeste da Bahia e no norte de Minas Gerais.

A prevalência do cultivo de bananeiras tipo Prata no País, com destaque para a 'Prata-Anã' e a 'Pacovan', evidencia a tradição de seu cultivo e a sua boa aceitação comercial. A despeito disso, a suscetibilidade à sigatoka-amarela, à sigatoka-negra e ao mal-do-panamá, aliada ao porte elevado, particularmente na 'Pacovan', destaca a importância do melhoramento genético na busca constante de materiais superiores aos de uso corrente pelos agricultores.

Assim, surgiram vários programas de melhoramento genético de bananeira: o Programa de Melhoramento de Musáceas da Fundação Hondurenha de Investigação Agrícola (Fhia) em 1959, o Programa de Melhoramento Genético de Bananeira da Jamaica (Móran, 2006) e o Programa Brasileiro de Melhoramento Genético da Bananeira - coordenado pela Embrapa Mandioca e Fruticultura Tropical, em 1983 (Silva et al., 2002)-, este último voltado para o desenvolvimento de cultivares tipo Prata e Maçã.

Decorrentes desses programas, diferentes cultivares tipo Prata foram disponibilizadas aos agricultores: Fhia-01 (BRS Fhia Maravilha), Fhia-18 (BRS Fhia-18) - referida como "falsa Fhia-18" (Santos et al., 2006; Braga Filho et al., 2008) -, e Fhia-18, verdadeira, introduzidas pela Fhia. Entre os muitos híbridos do programa brasileiro, há um tipo Prata em pré-lançamento, o PA42-44. Esses genótipos são híbridos tetraploides derivados da 'Prata-Anã'.

A avaliação do comportamento de genótipos de bananeira em diferentes ecossistemas é essencial ao programa de melhoramento genético. Trabalhos dessa natureza no Brasil iniciaram-se com Alves et al. (1984) e Moreira \& Saes (1984) e coincidiram com a implantação do Programa Brasileiro de Melhoramento da Bananeira em 1983, tendo-se intensificado a partir de 1997 com ensaios dos novos genótipos gerados e introduzidos pela Embrapa Mandioca e Fruticultura Tropical em vários ambientes.

Nesses estudos, normalmente se avaliam caracteres fenotípicos vegetativos e de rendimento, considerados relevantes para a identificação e a seleção de indivíduos superiores, sujeitos tanto à seleção natural quanto artificial (Vieira et al., 2005; Amorim et al., 2009). Entretanto, a maioria desses trabalhos têm avaliado cultivares de subgrupos e grupos genômicos diferentes, o que dificulta as comparações, em razão das características intrínsecas.

O presente trabalho teve por objetivo avaliar o comportamento fitotécnico da cultivar Prata-Anã $(\mathrm{AAB})$ e de quatro híbridos tetraploides (AAAB) descendentes, em dois ciclos de produção, nas condições do Perímetro Irrigado do Estreito, sudoeste da Bahia.

\section{Material e Métodos}

O experimento foi realizado entre maio de 2006 e maio de 2008, em lote de agricultor, no Perímetro Irrigado do Estreito III (Emsa), no Município de Sebastião Laranjeiras, BA, a $14^{\circ} 41^{\prime} 52^{\prime \prime} S 42^{\circ} 51^{\prime} 14^{\prime \prime}$ W e altitude de $548 \mathrm{~m}$. O solo é classificado como Latossolo Vermelho-Amarelo distrófico típico, de textura média, muito profundo, fase caatinga hipoxerófila, com relevo plano. As médias climáticas anuais de precipitação são de $826 \mathrm{~mm}$, temperatura média de $22^{\circ} \mathrm{C}$ e umidade relativa do ar de $70 \%$ (Companhia de Desenvolvimento dos Vales do São Francisco e do Parnaíba, 1985).

Foram avaliadas, em dois ciclos de produção (2006-2008), a variedade Prata-Anã (mutante da 'Branca' - Santa Catarina; grupo genômico AAB) e suas progênies, os híbridos de 'Prata-Anã' originados da Fundação Hondurenha de Investigação Agrícola (Fhia) do grupo genômico AAAB, Fhia-01 (BRS Fhia Maravilha), BRS Fhia-18, Fhia-18 (cruzamento 'Prata-Anã' x SH3263), e o híbrido tipo Prata originado da Embrapa, do grupo genômico AAAB, PA42-44 (cruzamento 'Prata-Anã' $\mathrm{x}$ M53). Os genótipos têm a seguinte descrição: 'Prata-Anã', porte médio, produtividade média e suscetível à sigatoka-amarela, à sigotoka-negra e ao mal-do-panamá; Fhia-01, frutos tipo Prata, planta resistente à sigatoka-negra e mal-do-panamá, moderadamente resistente à sigatoka-amarela; BRS Fhia-18, frutos tipo Prata que despencam com facilidade, resistente à sigatoka-negra, moderadamente resistente à sigatoka-amarela $\mathrm{e}$ suscetível ao mal-do-panamá; Fhia-18, frutos tipo Prata-Anã, tolerante à sigatoka-amarela, resistente ao mal-do-panamá, introduzida da Fhia por agricultores; PA42-44, planta e fruto tipo Prata-Anã, porte médio, produtividade média e resistente à sigatoka-amarela $\mathrm{e}$ ao mal-do-panamá.

$\mathrm{Na}$ instalação do experimento, foram utilizadas mudas micropropagadas e sistema de irrigação por microaspersão. A implantação e os tratos culturais 
seguiram as recomendações para a cultura adotadas pelos produtores no Perímetro Irrigado do Estreito. Não foi utilizado controle químico para a sigatoka-amarela, nem para qualquer outro problema fitossanitário.

Foram mensurados os seguintes descritores fenotípicos vegetativos e de rendimento: altura da planta, perímetro do pseudocaule, número de folhas vivas no florescimento e na colheita; número de filhos emitidos; avaliação de sigatoka-amarela no florescimento e na colheita, mediante o uso da escala de notas - planta sem sintomas (1), estrias nas folhas velhas (2), poucas lesões nas folhas velhas (3), muitas lesões apenas nas folhas velhas (4), folhas velhas bastante atacadas com estrias nas folhas mais novas (5), planta com sintomas nas folhas velhas e novas (6) -; tempo entre plantio e florescimento, entre plantio e colheita e do florescimento à colheita; número de pencas e de frutos por cacho; comprimento e diâmetro dos frutos; e produtividade estimada conforme Robinson \& Nel (1988): $\left(\mathrm{Mg} \mathrm{ha}^{-1}\right.$ por ano $)=\left[\right.$ produção $\left(\mathrm{Mg} \mathrm{ha}^{-1}\right) /$ duração do ciclo (meses)] x 12, em dois ciclos de produção (mãe e filho), conforme Silva et al. (1999) e Donato et al. (2006).

$\mathrm{O}$ delineamento experimental foi inteiramente casualizado, com 5 tratamentos (Tabela 1) e 10 repetições, no total de 50 unidades experimentais, constituídas por uma planta útil e espaçamento de $3 \times 2,5 \mathrm{~m}$, com bordadura externa ao ensaio. Submeteram-se os dados à análise de variância, e as médias de cada tratamento foram comparadas pelo teste de Tukey, a 5\% de probabilidade.

\section{Resultados e Discussão}

Ocorreram diferenças significativas entre as cultivares, na maioria das características, à época do florescimento, nos dois ciclos de produção, exceto para o número de filhos (Tabela 1), o que comprova a variabilidade existente nas cultivares avaliadas, mesmo em híbridos tetraploides do grupo genômico $\mathrm{AAAB}$ provenientes do mesmo genitor feminino, a 'Prata-Anã' (AAB).

$\mathrm{Na}$ característica altura de plantas, ocorreram diferenças significativas entre as cultivares Fhia-18, BRS Fhia-18 e Fhia-01, no primeiro ciclo (Tabela 1). As cultivares Prata-Anã e PA42-44 não diferiram entre si, nem da Fhia-01 e nem da BRS Fhia-18. No segundo ciclo de produção, a cultivar Fhia-18 diferiu da BRS Fhia-18 e da 'Prata-Anã', que foram similares a Fhia 01 e PA42-44. A maior altura de plantas no primeiro e segundo ciclos foi observada no híbrido Fhia-18. Os valores registrados nas cultivares BRS Fhia-18, Fhia-01 e Prata-Anã discordam dos encontrados em Jaíba, MG, onde as maiores alturas foram de Fhia-01 e BRS Fhia-18 (Silva et al., 2003), e em Guanambi, BA, onde a 'Prata-Anã' apresentou maior altura em comparação aos híbridos citados (Donato et al., 2003).

Aumento e estabilidade da altura, nos ciclos posteriores, foram observados por vários autores (Silva et al., 2002; Donato et al., 2003, 2006; Silva et al., 2003; Lima et al., 2005; Rodrigues et al., 2006; Ledo et al., 2008; Oliveira et al., 2008), com o maior incremento do primeiro para o segundo ciclo (Alves et al., 1984; Silva et al., 2002). A partir do terceiro ciclo, normalmente não há mais aumento na altura das plantas (Belalcázar Carvajal, 1991; Soto Ballestero, 2008).

Porte baixo é característica desejável e pode influenciar a produtividade, com velocidade de vento elevada, como constatado em estudo por Donato et al. (2006) em que, independentemente do grupo genômico, os genótipos de porte mais baixo foram mais produtivos que os de porte mais alto.

Oliveira et al. (2008) verificaram manutenção do caráter altura do genitor feminino 'Prata-Anã' no híbrido

Tabela 1. Caracteres avaliados na época do florescimento, em cultivares de bananeira Prata, no Perímetro Irrigado de Estreito, sudoeste da Bahia, em 2006-2008 ${ }^{(1)}$.

\begin{tabular}{|c|c|c|c|c|c|c|c|c|c|c|}
\hline \multirow[t]{2}{*}{ Cultivar } & \multicolumn{2}{|c|}{$\begin{array}{l}\text { Altura de planta } \\
(\mathrm{cm})\end{array}$} & \multicolumn{2}{|c|}{$\begin{array}{c}\text { Perimetro } \\
\text { de pseudocaule }(\mathrm{cm})\end{array}$} & \multicolumn{2}{|c|}{$\begin{array}{l}\text { Número de filhos } \\
\text { emitidos }\end{array}$} & \multicolumn{2}{|c|}{$\begin{array}{l}\text { Número } \\
\text { de folhas }\end{array}$} & \multicolumn{2}{|c|}{ Sigatoka-amarela } \\
\hline & $1^{\circ}$ ciclo & $2^{\circ}$ ciclo & $1^{\circ}$ ciclo & $2^{\circ}$ ciclo & $1^{\circ}$ ciclo & $2^{\circ}$ ciclo & $1^{\circ}$ ciclo & $2^{\circ}$ ciclo & $1^{\circ}$ ciclo & $2^{\frac{0}{} \text { ciclo }}$ \\
\hline Fhia-18 & $365 a$ & $437 \mathrm{a}$ & $96 a$ & $110 \mathrm{a}$ & $5 a$ & $3 a$ & $13,1 \mathrm{ab}$ & $12,9 \mathrm{ab}$ & $2,1 \mathrm{c}$ & $3,0 \mathrm{a}$ \\
\hline BRS Fhia-18 & $271 \mathrm{c}$ & $395 b$ & $80 \mathrm{~b}$ & $94 b$ & $5 a$ & $3 a$ & $11,0 \mathrm{~b}$ & $11,7 \mathrm{~b}$ & $3,0 \mathrm{~b}$ & $3,0 \mathrm{a}$ \\
\hline Fhia-01 & $295 b$ & $401 \mathrm{ab}$ & $84 b$ & $92 b$ & $5 a$ & $3 a$ & $11,2 b$ & $11,2 b$ & $3,0 \mathrm{~b}$ & $2,7 \mathrm{a}$ \\
\hline Prata-Anã & $281 b c$ & $379 b$ & $82 b$ & $101 b$ & $5 a$ & $3 a$ & $14,5 \mathrm{a}$ & $15,1 \mathrm{a}$ & $5,4 a$ & $2,3 a$ \\
\hline PA42-44 & $285 b c$ & $405 \mathrm{ab}$ & $83 b$ & $98 \mathrm{~b}$ & $5 \mathrm{a}$ & $2 \mathrm{a}$ & $12,3 \mathrm{ab}$ & $14,1 \mathrm{a}$ & $1,0 \mathrm{~d}$ & $1,0 \mathrm{~b}$ \\
\hline CV (\%) & 5,75 & 7,42 & 7,05 & 6,66 & 17,72 & 31,85 & 11,60 & 12,50 & 18,75 & 27,9 \\
\hline
\end{tabular}

${ }^{(1)}$ Médias seguidas de letras iguais, nas colunas, não diferem estatisticamente pelo teste de Tukey, a $5 \%$ de probabilidade. 
PA42-44, também constatado por Donato et al. (2006) e no presente trabalho, nos dois ciclos de produção, pois ambas as cultivares não diferiram estatisticamente.

Quanto ao caráter perímetro do pseudocaule, o híbrido Fhia-18 diferiu das demais cultivares avaliadas (Tabela 1), com maior desenvolvimento vegetativo nos dois ciclos de produção. Silva et al. (2002) obtiveram resultados diferentes, em que o maior diâmetro do pseudocaule foi o da 'Prata-Anã' em comparação ao do BRS Fhia-18. Oliveira et al. (2007) também observaram que 'Prata-Anã' e Fhia-01 apresentaram maiores médias.

Ocorreram incrementos nas médias dessa característica, ao longo dos ciclos, em todas as cultivares avaliadas, como observado em outros trabalhos (Donato et al., 2003, 2006; Rodrigues et al., 2006; Ledo et al., 2008). O perímetro de pseudocaule está relacionado ao vigor da planta e à capacidade de sustentação do cacho e suscetibilidade ao tombamento (Silva et al., 2003).

As cultivares não diferiram em relação ao número de filhos emitidos nos dois ciclos avaliados (Tabela 1). Resultados semelhantes foram obtidos por Silva et al. (2006) em clones de banana 'Cavendish', o que permite inferir que esta característica apresenta pouca variação dentro do mesmo grupo genômico. No entanto, Pereira et al. (2003) observaram menor perfilhamento para os híbridos Fhia-01 e BRS Fhia-18 que para a 'Prata-Anã'.

O maior número de folhas no florescimento foi observado em Fhia-18, PA42-44 e 'Prata-Anã' que não diferiram entre si nos dois ciclos de produção (Tabela 1). As cultivares Fhia-01 e BRS Fhia-18 apresentaram os menores números de folhas na emissão do cacho, sem diferenças significativas nos dois ciclos. Os resultados assemelham-se aos obtidos por Donato et al. (2003, 2006), que comprovaram a superioridade da 'Prata-Anã' quanto ao número de folhas no florescimento. Esta cultivar, embora mais suscetível à sigatoka-amarela, teve mais folhas, provavelmente em razão da baixa incidência da sigatoka-amarela no local.

$\mathrm{Na}$ avaliação de sigatoka-amarela no florescimento, o híbrido PA42-44 se mostrou mais resistente, sem apresentar sintomas da doença nos dois ciclos e tendo diferido significativamente das outras cultivares (Tabela 1). A 'Prata-Anã' foi a mais suscetível, o que corrobora os resultados de Siviero \& Ledo (2002), enquanto os demais híbridos foram moderadamente resistentes. Rodrigues et al. (2006) também observaram severidade maior da doença em 'Prata-Anã' e severidade mediana nos híbridos Fhia-01 e BRS Fhia-18, o que é corroborado pelo presente trabalho.

Quanto ao período para o florescimento no primeiro ciclo, Fhia-18 foi o último a florescer, a 'Prata-Anã' foi intermediária, e houve diferença significativa apenas entre Fhia-18 e os outroshíbridos(Tabela2). No segundo ciclo, os híbridos BRS Fhia-18 e PA42-44 foram os mais precoces, tendo diferido significativamente da 'Prata-Anã', de Fhia-01 e Fhia-18; este último foi mais tardio, como no ciclo anterior. Resultados encontrados por Silva et al. (2003) e Oliveira et al. (2007) também demonstraram as vantagens da precocidade. De modo semelhante, Donato et al. (2006) verificaram maior precocidade para o híbrido PA42-44 em comparação à genitora, no segundo ciclo de produção.

A precocidade da floração é uma característica importante, pois diminui o tempo de exposição da planta aos patógenos e, consequentemente, pode garantir maior número de folhas no momento da diferenciação floral, o que favorece maior quantidade de flores femininas na inflorescência (Robinson, 1996) e resulta em cachos com maior número de pencas.

$\mathrm{O}$ período do florescimento à colheita, no primeiro ciclo, variou de 142 a 167 dias em BRS Fhia-18 e

Tabela 2. Período (dias) do plantio ao florescimento, do florescimento à colheita e do plantio à colheita de cultivares de bananeira Prata avaliadas no Perímetro Irrigado de Estreito, sudoeste da Bahia, em 2006 a $2008^{(1)}$.

\begin{tabular}{|c|c|c|c|c|c|c|}
\hline \multirow[t]{2}{*}{ Cultivar } & \multicolumn{2}{|c|}{ Plantio ao florescimento } & \multicolumn{2}{|c|}{ Florescimento à colheita } & \multicolumn{2}{|c|}{ Plantio à colheita } \\
\hline & $1^{\circ}$ ciclo & $2^{\circ}$ ciclo & $1^{\circ}$ ciclo & $2^{\circ}$ ciclo & $1^{\circ}$ ciclo & $2^{-}$ciclo \\
\hline Fhia-18 & $309 a$ & $526 a$ & $150 \mathrm{ab}$ & $140 \mathrm{ab}$ & $460 \mathrm{a}$ & $666 \mathrm{ab}$ \\
\hline BRS Fhia-18 & $218 b$ & $376 \mathrm{c}$ & $142 b$ & $125 \mathrm{bc}$ & $360 \mathrm{c}$ & $501 d$ \\
\hline Fhia-01 & $238 b$ & $476 \mathrm{ab}$ & $153 \mathrm{ab}$ & $123 c$ & $391 b c$ & $599 b c$ \\
\hline Prata-Anã & $260 \mathrm{ab}$ & $563 a$ & $167 \mathrm{a}$ & $137 \mathrm{abc}$ & $428 \mathrm{ab}$ & $701 \mathrm{a}$ \\
\hline PA42-44 & $218 b$ & $425 \mathrm{bc}$ & $154 \mathrm{ab}$ & $143 a$ & $371 \mathrm{c}$ & $567 \mathrm{~cd}$ \\
\hline $\mathrm{CV}(\%)$ & 17,06 & 15,62 & 10,34 & 9,67 & 9,62 & 11,24 \\
\hline
\end{tabular}

${ }^{(1)}$ Médias seguidas de letras iguais, nas colunas, não diferem entre si pelo teste de Tukey, a 5\% de probabilidade. 
'Prata-Anã', respectivamente (Tabela 2). Os híbridos, exceto BRS Fhia-18, não diferiram significativamente da genitora. No segundo ciclo, todos os genótipos diminuíram o tempo entre florescimento e colheita. As médias variaram de 123 dias para Fhia 01, a mais precoce, até 143 dias para PA42-44, a mais tardia. O período de florescimento dos híbridos, em comparação ao da 'Prata-Anã', foi semelhante ao do primeiro ciclo, mas sem diferença significativa. No entanto, entre os híbridos PA42-44, Fhia-18 e Fhia-01 houve diferenças significativas. Resultados similares foram obtidos por Santos et al. (2006), no sudoeste de Goiás. No norte de Minas Gerais, a BRS Fhia-18 demorou menos entre florescimento e colheita do que a genitora (Rodrigues et al., 2006).

Todos os híbridos, exceto Fhia-18, demoraram menos entre o plantio e a colheita do que a 'Prata-Anã'. No entanto, não houve diferença entre a média da 'Prata-Anã' e a de Fhia-01 (Tabela 2). BRS Fhia-18 e PA42-44 foram os híbridos mais precoces, e Fhia-18 foi o mais tardio. No segundo ciclo, com exceção de Fhia-18, os demais híbridos diferiram significativamente da genitora. 'Prata-Anã' foi a variedade mais tardia e BRS Fhia-18, a mais precoce.

Donato et al. (2003) constataram maior precocidade na colheita do cacho em BRS Fhia-18 em comparação à 'Prata-Anã', embora Fhia-01 tenha sido mais tardia. Entretanto, Rodrigues et al. (2006) e Gonçalves et al. (2008) relataram maior precocidade do genitor feminino, em comparação com seus híbridos Fhia-01 e BRS Fhia-18, no norte de Minas Gerais. Lins (2005) e Donato et al. (2006) observaram maior precocidade para o híbrido PA42-44 em comparação à sua genitora. Em geral, a maioria dos trabalhos (Silva et al., 2002, 2003; Santos et al., 2006; Oliveira et al., 2007; Ledo et al., 2008) relatam maior precocidade no florescimento e na colheita dos híbridos, o que era esperado, particularmente nos originados do Programa da Fhia, embora Fhia-18, também da mesma origem, tenha se mostrado muito tardio.

Quanto à avaliação de sigatoka-amarela, na época da colheita, os híbridos e a cultivar Prata-Anã diferiram (Tabela 3). A maior suscetibilidade foi da 'Prata-Anã' e a menor foi a do PA42-44, o que era esperado, pois a genitora e esse híbrido são, respectivamente, suscetível e resistente à sigatoka-amarela. Os demais híbridos foram intermediários, ou seja, moderadamente suscetíveis à doença. No segundo ciclo de produção, a sucetibilidade dos genótipos foi similar à do primeiro ciclo.

Em relação ao número de folhas vivas à época da colheita, no primeiro ciclo de produção, as cultivares não diferiram estatisticamente (Tabela 3 ). No segundo ciclo de produção, ocorreram diferenças significativas entre PA42-44 e 'Prata-Anã', que apresentaram os maiores números de folhas, e entre Fhia-01 e Fhia-18, com menor número de folhas.

Os resultados encontrados por Donato et al. (2006) em Guanambi, local sem sigatoka-amarela e que apresenta ventos fortes, mostram similaridade estatística entre PA42-44 e sua genitora quanto ao número de folhas vivas, porém com maiores valores em comparação com este trabalho, na presença de sigatoka-amarela. Lins (2005) em Una, sul da Bahia, região com maior severidade de sigatoka-amarela, observou semelhança estatística entre PA42-44 e 'Prata-Anã', no primeiro ciclo, porém com valores bem inferiores aos do presente trabalho e diferença significativa no segundo ciclo. Em região com presença de sigatoka-negra (Rio Branco, Acre), Oliveira et al. (2008) verificaram diferenças significativas entre o híbrido PA42-44 e a genitora.

Tabela 3. Caracteres avaliados na época da colheita, em cultivares de bananeira Prata, no Perímetro Irrigado de Estreito, sudoeste da Bahia, em 2006-2008 ${ }^{(1)}$.

\begin{tabular}{|c|c|c|c|c|c|c|c|c|c|c|c|c|}
\hline \multirow[t]{2}{*}{ Cultivar } & \multicolumn{2}{|c|}{$\begin{array}{l}\text { Número } \\
\text { de folhas }\end{array}$} & \multicolumn{2}{|c|}{ Sigatoka-amarela } & \multicolumn{2}{|c|}{$\begin{array}{l}\text { Número } \\
\text { de pencas }\end{array}$} & \multicolumn{2}{|c|}{$\begin{array}{l}\text { Número } \\
\text { de frutos }\end{array}$} & \multicolumn{2}{|c|}{$\begin{array}{l}\text { Comprimento } \\
\text { do fruto }(\mathrm{cm})\end{array}$} & \multicolumn{2}{|c|}{$\begin{array}{c}\text { Diâmetro } \\
\text { do fruto }(\mathrm{mm})\end{array}$} \\
\hline & $1^{\circ}$ ciclo & $22^{-}$ciclo & $1^{\circ}$ ciclo & $\overline{2^{\circ} \text { ciclo }}$ & $1^{\circ}$ ciclo & $2^{\circ}$ ciclo & $1^{\circ}$ ciclo & $2^{\circ}$ ciclo & $1^{\circ}$ ciclo & $2^{\circ}$ ciclo & $1^{\circ}$ ciclo & $2^{\circ}$ ciclo \\
\hline Fhia-18 & $5,3 \mathrm{a}$ & $8,2 \mathrm{c}$ & $4,4 \mathrm{~b}$ & $3,0 \mathrm{~b}$ & $10 \mathrm{a}$ & $12 \mathrm{a}$ & $160 \mathrm{a}$ & $212 \mathrm{a}$ & $18 \mathrm{a}$ & $17 b c$ & $33 a$ & $35 \mathrm{ab}$ \\
\hline BRS Fhia-18 & $6,5 \mathrm{a}$ & $9,1 b c$ & $3,0 \mathrm{c}$ & $3,1 b$ & $10 \mathrm{a}$ & $11 \mathrm{ab}$ & $145 \mathrm{ab}$ & $174 b$ & $18 \mathrm{a}$ & $20 \mathrm{a}$ & $34 a$ & $38 \mathrm{a}$ \\
\hline Fhia-01 & $6,6 a$ & $8,6 \mathrm{c}$ & $3,9 b$ & $2,1 \mathrm{c}$ & $10 \mathrm{a}$ & $10 \mathrm{bc}$ & $146 \mathrm{ab}$ & $170 \mathrm{~b}$ & $18 \mathrm{a}$ & $19 a$ & $33 a$ & $36 \mathrm{ab}$ \\
\hline Prata-Anã & $5,3 a$ & $11,0 \mathrm{ab}$ & $6,0 \mathrm{a}$ & $4,4 a$ & $9 a$ & $11 \mathrm{ab}$ & $135 b$ & $161 b$ & $14 b$ & $16 \mathrm{c}$ & $32 \mathrm{a}$ & $34 b$ \\
\hline PA42-44 & $7,0 \mathrm{a}$ & $11,3 \mathrm{a}$ & $1,0 \mathrm{~d}$ & $1,0 \mathrm{~d}$ & $8 b$ & $9 \mathrm{c}$ & $105 \mathrm{c}$ & $126 \mathrm{c}$ & $17 \mathrm{a}$ & $19 a$ & $34 \mathrm{a}$ & $37 \mathrm{a}$ \\
\hline$\overline{\mathrm{CV}(\%)}$ & 26,93 & 16,87 & 17,89 & 25,82 & 11,70 & 11,60 & 13,01 & 13,31 & 7,80 & 9,15 & 6,90 & 7,86 \\
\hline
\end{tabular}

${ }^{(1)}$ Médias seguidas de letras iguais, nas colunas, não diferem entre si pelo teste de Tukey, a 5\% de probabilidade. 
Em geral, os dados encontrados neste trabalho e nos trabalhos de outros autores atestam maior retenção de folhas, na época da colheita, no híbrido PA42-44 em comparação à sua genitora, em presença de sigatoka-amarela, principalmente em áreas com maior severidade da doença e na presença de sigatoka-negra. Nas demais cultivares, ocorreu decréscimo no número de folhas.

Com relação ao número de pencas na colheita, apenas o híbrido PA42-44 diferiu significativamente da 'Prata-Anã' (Tabela 3). Os demais híbridos não diferiram estatisticamente da genitora. No segundo ciclo, os genótipos apresentaram maior número de pencas em comparação ao primeiro ciclo. Esses resultados corroboram os de Lins (2005) quanto à 'Prata-Anã' e seu híbrido PA42-44 com relação ao maior número de pencas apresentado pela genitora, no entanto os valores foram sensivelmente menores em comparação com os obtidos no presente trabalho. O número de pencas no cacho tem grande influência em seu tamanho e peso, pois é parte deste e está relacionado diretamente à produtividade (Silva et al., 2002).

Diferenças significativas no número de frutos foram registradas entre Fhia-18, 'Prata-Anã' e PA42-44, no primeiro ciclo, enquanto Fhia-18 e PA42-44 não diferiram de Fhia-01 e BRS Fhia-18 (Tabela 3). Fhia-18 exibiu as maiores médias, e PA42-44, as menores médias, nos dois ciclos. A superioridade dos híbridos Fhia-01 e BRS Fhia-18 em relação à genitora foi constatada por Silva et al. (2003) ao comparar número de frutos em dois ciclos e em cinco ambientes. Lins (2005) e Donato et al. (2006) encontraram diferenças significativas entre 'Prata-Anã' e PA42-44 no número de frutos, com maiores valores para a genitora, similarmente aos resultados do presente trabalho.

O comprimento e o diâmetro do fruto são características importantes na classificação comercial da banana. Como esperado, a progênie da 'Prata-Anã' mostrou-se superior, com frutos mais compridos, nos dois ciclos (Tabela 3). Apenas Fhia-18 não diferiu da genitora, no segundo ciclo. Silva et al. (2003), Lins (2005) e Donato et al. (2006) observaram superioridade dos híbridos para esse caráter.

Todos os genótipos apresentaram diâmetro de frutos semelhantes, sem diferença significativa entre as suas médias no primeiro ciclo (Tabela 3 ). No segundo ciclo, os híbridos BRS Fhia-18 e PA42-44 apresentaram diferença significativa da 'Prata-Anã', enquanto Fhia-18 e Fhia-01 apresentaram médias intermediárias, que não diferiram significativamente de 'Prata-Anã'. Lins (2005) e Donato et al. (2006) também encontraram, para este caráter, superioridade do híbrido PA42-44, em comparação com sua genitora, o que era esperado, pois os híbridos normalmente apresentam tamanhos de fruto superiores aos das variedades.

A produtividade dos híbridos no primeiro ciclo foi superior, exceto para o híbrido PA42-44, que não diferiu da genitora (Tabela 4).

No segundo ciclo, apenas houve diferença significativa na produtividade do BRS Fhia-18, superior à da 'Prata-Anã'. A superioridade dos híbridos em produtividade foi demonstrada em outros trabalhos (Silva et al., 2002; Pereira et al., 2003; Silva et al., 2003; Rodrigues et al., 2006; Santos et al., 2006; Gonçalves et al., 2008). O híbrido PA42-44 não diferiu significativamente da genitora quanto à produtividade, nos dois ciclos avaliados, embora 'Prata-Anã' seja superior em número de frutos e pencas, e PA42-44 seja resistente à sigatoka-amarela. Esses resultados concordam com Donato et al. (2006) em local sem ocorrência de sigatoka-amarela, com Lins (2005) na presença de elevada severidade de sigatoka-amarela e com Ledo et al. (2008). Em presença de sigatoka-negra, Oliveira et al. (2008) observaram produtividade maior e estatisticamente diferente para PA42-44 em comparação à da genitora.

$\mathrm{O}$ fato de cultivares com tolerância intermediária à sigatoka, como Fhia-18, BRS Fhia-18 e Fhia-01, mesmo em presença da doença, apresentarem produtividade superior à do híbrido com maior grau de resistência (PA42-44), provavelmente está associado ao maior potencial produtivo das cultivares desenvolvidas pelo Programa de Melhoramento da Fhia.

Tabela 4. Produtividade $\left(\mathrm{Mg} \mathrm{ha}^{-1}\right.$ por ciclo) de cultivares de bananeira Prata avaliadas no Perímetro Irrigado de Estreito, sudoeste da Bahia, de 2006 a $2008^{(1)}$.

\begin{tabular}{|c|c|c|c|c|}
\hline \multirow[t]{2}{*}{ Cultivares } & \multicolumn{2}{|c|}{ Peso de cacho } & \multicolumn{2}{|c|}{ Peso de penca } \\
\hline & $1^{\circ}$ ciclo & $2^{\underline{0}}$ ciclo & $1^{\circ}$ ciclo & $2^{\circ}$ ciclo \\
\hline Fhia-18 & $32,1 \mathrm{a}$ & $49,9 a b$ & $27,5 \mathrm{a}$ & $44,1 \mathrm{ab}$ \\
\hline BRS Fhia-18 & $37,8 \mathrm{a}$ & $67,8 \mathrm{a}$ & $33,0 \mathrm{a}$ & $60,5 a$ \\
\hline Fhia-01 & $31,9 \mathrm{a}$ & $47,4 \mathrm{ab}$ & $27,8 \mathrm{a}$ & $42,4 \mathrm{ab}$ \\
\hline Prata-Anã & $21,3 b$ & $34,2 b$ & $18,5 \mathrm{~b}$ & $30,6 b$ \\
\hline PA42-44 & $25,4 b$ & $43,1 b$ & $22,0 \mathrm{~b}$ & $38,7 \mathrm{~b}$ \\
\hline CV (\%) & 21,67 & 25,43 & 21,82 & 25,26 \\
\hline
\end{tabular}

${ }^{(1)}$ Médias seguidas de letras iguais, nas colunas, não diferem entre si pelo teste de Tukey, a $5 \%$ de probabilidade. 


\section{Conclusões}

1. Os híbridos BRS Fhia-18, Fhia-01 (BRS Fhia Maravilha) e PA42-44 apresentam precocidade e frutos com boa classificação comercial quanto ao comprimento e diâmetro.

2. Os híbridos BRS Fhia-18, Fhia-18 e Fhia-01 (BRS Fhia Maravilha) são mais produtivos que a 'Prata-Anã'.

3. A cultivar Prata-Anã é a mais suscetível à sigatoka-amarela e o híbrido PA42-44, o mais resistente, porém similar em produtividade.

\section{Referências}

ALVES, E.J.; SHEPHERD, K.; FERREIRA, F.R. Caracterização e avaliação de germoplasma de banana (Musa spp.). In: CONGRESSO BRASILEIRO DE FRUTICULTURA, 7., 1984, Florianópolis. Anais. Florianópolis: Sociedade Brasileira de Fruticultura, 1984. p.202-214.

AMORIM, E.P.; LESSA, L.S.; LEDO, C.A. da S.; AMORIM, V.B. de O.; REIS, R.V.; SANTOS-SEREJO, J.A. dos; SILVA, S. de O e. Caracterização agronômica e molecular de genótipos diplóides melhorados de bananeira. Revista Brasileira de Fruticultura, v.31, p.154-161, 2009.

ATER. Relatório mensal de produção do Perímetro Irrigado do Estreito. DIPE: Urandi, 2008. 20p.

BELALCÁZAR CARVAJAL, S.L. El cultivo del plátano en el trópico. Cali: Feriva, 1991. 376p.

BRAGA FILHO, J.R.; NASCIMENTO, J.L. do; NAVES, R.V.; SILVA, L.B. e; PEREIRA, A.C. da C.P.; GONÇALVES, H.M.; RODRIGUES, C. Crescimento e desenvolvimento de cultivares de bananeira irrigadas. Revista Brasileira de Fruticultura, v.30, p.981-988, 2008.

COMPANHIA DE DESENVOLVIMENTO DOS VALES DO SÃO FRANCISCO E DO PARNAÍBA. Levantamento semi-detalhado de solos: classificação de terras para irrigação. Brasília: Codevasf, 1985. 381p.

DONATO, S.L.R.; SILVA, S. de O.; LUCCA FILHO, O.A.; LIMA, M.B.; DOMINGUES, H.; ALVES, J.da S. Comportamento de variedades e híbridos de bananeira (Musa spp.), em dois ciclos de produção no sudoeste da Bahia. Revista Brasileira de Fruticultura, v.28, p.139-144, 2006.

DONATO, S.L.R.; SILVA, S. de O. e; PASSOS, A.R.; LIMA NETO, F.P.; LIMA, M.B. Avaliação de variedades e híbridos de bananeira sob irrigação. Revista Brasileira de Fruticultura, v.25, p.348-351, 2003.

GONÇALVES, V.D.; NIETSCHE, S.; PEREIRA, M.C.T.; SILVA, S. de O. e; SANTOS, T.M. dos; OLIVEIRA, J.R.; FRANCO, L.R.L.; RUGGIERO, C. Avaliação das cultivares de bananeira Prata-Anã, Thap Maeo e Caipira em diferentes sistemas de plantio no norte de Minas Gerais. Revista Brasileira de Fruticultura, v.30, p.371-376, 2008.
LEDO, A. da S.; SILVA JÚNIOR, J.F. da; LEDO, C.A. da S.; SILVA, S. de O. e. Avaliação de genótipos de bananeira na região do Baixo São Francisco, Sergipe. Revista Brasileira de Fruticultura, v.30, p.691-695, 2008.

LIMA, M.B.; SILVA, S. de O. e; JESUS, O.N. de; OLIVEIRA, W.S.J. de; GARRIDO, M. da S.; AZEVEDO, R.L. Avaliação de cultivares e híbridos de bananeira no Recôncavo Baiano. Ciência e Agrotecnologia, v.29, p.515-520, 2005.

LINS, R.D. Avaliação de genótipos de bananeira em dois ciclos de produção no Município de Una, Bahia. 2005. 55p. Dissertação (Mestrado) - Universidade Federal da Bahia, Cruz das Almas.

MORÁN, J.F.A. Híbridos de banana desenvolvidos pela Fhia. In: REUNIÃO INTERNACIONAL ACORBAT, 17., 2006, Joinville. Bananicultura: um negócio sustentável: anais. Joinville: ACORBAT/ACAFRUTA, 2006. v.1, p.173-177.

MOREIRA, R.S.; SAES, L.A. Considerações sobre o banco de germoplasma do IAC. In: CONGRESSO BRASILEIRO DE FRUTICULTURA, 7., 1984, Florianópolis. Anais. Florianópolis: SBF/EMPASC, 1984. v.1, p.220-236.

OLIVEIRA, C.A.P. de; PEIXOTO, C.P.; SILVA, S. de O. e; LEDO, C.A. da S.; SALOMÃO, L.C.C. Genótipos de bananeira em três ciclos na Zona da Mata mineira. Pesquisa Agropecuária Brasileira, v.42, p.173-181, 2007.

OLIVEIRA, T.K. de; LESSA, L.S.; SILVA, S. de O. e; OLIVEIRA, J.P. de. Características agronômicas de genótipos de bananeira em três ciclos de produção em Rio Branco, AC. Pesquisa Agropecuária Brasileira, v.43, p.1003-1010, 2008.

PEREIRA, L.V.; SILVA, S. de O. e; ALVES, E.J.; SILVA, C.R. de R. e. Avaliação de cultivares e híbridos de bananeira em Lavras, MG. Ciência e Agrotecnologia, v.27, p. 17-25, 2003.

ROBINSON, J.C. Bananas and plantains. Oxon: CAB International, 1996. 238p.

ROBINSON, J.C.; NEL, D.J. Plant density studies with banana (cv. Williams) in a subtropical climate. I. Vegetative morphology, phenology and plantation microclimate. Journal of Horticultural Science, v.63, p.303-313, 1988.

RODRIGUES, M.G.V.; SOUTO, R.F.; SILVA, S. de O. e. Avaliação de genótipos de bananeira sob irrigação. Revista Brasileira de Fruticultura, v.28, p.444-448, 2006.

SANTOS, S.C.; CARNEIRO, L.C.; SILVEIRA NETO, A.N. da; PANIAGO JÚNIOR, E.; FREITAS, H.G. de; PEIXOTO, C.N. Caracterização morfológica e avaliação de cultivares de bananeira resistentes à sigatoka-negra (Mycosphaerella fijiensis Morelet) no sudoeste goiano. Revista Brasileira de Fruticultura, v.28, p.449-553, 2006.

SILVA, S. de O. e; CARVALHO, P.C.L. de; SHEPHERD, K.; ALVES, E.J.; OLIVEIRA, C.A.P. de; CARVALHO, J.A.B.S. Catálogo de germoplasma de bananeira (Musa spp.). Cruz das Almas: Embrapa Mandioca e Fruticultura, 1999. 100p.

SILVA, S. de O. e; FLORES, J.C. de O.; LIMA NETO, F.P. Avaliação de cultivares e híbridos de bananeira em quatro ciclos de produção. Pesquisa Agropecuária brasileira, v.37, p.1567-1574, 2002. 
SILVA, S. de O. e; PASSOS, A.R.; DONATO, S.L.R.; SALOMÃO, L.C.C.; PEREIRA, L.V.; RODRIGUES, M.G.V.; LIMA NETO, F.P.; LIMA, M.B. Avaliação de genótipos de bananeira em diferentes ambientes. Ciência e Agrotecnologia, v.24, p.737-748, 2003.

SILVA, S. de O. e; PIRES, E.T.; PESTANA, R.K.N.; ALVES, J. da S.; SILVEIRA, D. de C. Avaliação de clones de banana Cavendish. Ciência e Agrotecnologia, v.30, p.832-837, 2006.

SILVA, S. de O. e; ROCHA, S.A.; ALVES, E.J.; CREDICO, M.DI.; PASSOS, A.R. Caracterização morfológica e avaliação de cultivares e híbridos de bananeira. Revista Brasileira de Fruticultura, v.22, p.61-169, 2000.
SIVIERO, A.; LEDO, A. da S. Avaliação de genótipos de banana à sigatoca-amarela na Amazônia Ocidental. Revista Brasileira de Fruticultura, v.24, p.724-726, 2002.

SOTO BALLESTERO, M. Bananos: técnicas de produción, poscosecha y comercialización. 3.ed. San José: Litografía e Imprenta Lil, 2008. 1 CD-ROM.

VIEIRA, E.A.; CARVALHO, F.I.F. de; OLIVEIRA, A.C. de; BENIN, G.; ZIMMER, P.D.; SILVA, J.A.G. da; MARTINS, A.F.; BERTAN, I.; SILVA, G.O. da; SCHMIDT, D.A.M. Comparação entre medidas de distância genealógica, morfológica e molecular em aveia em experimentos com e sem a aplicação de fungicida. Bragantia, v.64, p.51-60, 2005.

$\overline{\text { Recebido em } 20 \text { de julho de } 2009 \text { e aprovado em } 10 \text { de novembro de } 2009}$ 